\title{
Capacity Building Indicators for Faculty Development Programs
}

\author{
Kiran Fatima Bana, Talea Hoor, Kulsoom Fatima Rizvi \\ How to cite this Article: \\ Bana KF, Hoor T, Rivi KF. Capacity Building Indicators for Faculty Development Programs J Bahria Uni Med Dental Coll. 2020;11(2):47- \\ 49. DOI: https://doi.org/10.51985/GVET5958 \\ This is an Open Access article distributed under the terms of the Creative Commons Attriution Non Commercial Liciense (http:// creativecommons/org/licences/by-nc/4.0) \\ which permits unrestricted non commercial use, distribution and reproduction in any medium, provided the original work is properly cited.
}

-

Capacity development targets the changes occurs in human behavior in response to learn any new skills, knowledge, behavior and values overtime within complex organization setting. This development process indicates the progressive readiness of human resource to perform in complex environment. Similarly, this growth process of individual would reflect when dealing with others. ${ }^{1}$

There is continuous revolution in medical education for last thirty years to ensure patient safety. Due to complexity in healthcare standards, emerging new trends of diseases; continuous quality improvement are the important milestones of healthcare delivery. ${ }^{2}$ Continuous quality improvement can be assessed by incorporating new technologies / innovations in healthcare delivery and impact of educational theories into goal settings and desired outcomes. Conventionally; stereo-typed medical educators owned subject knowledge acquired by their own teaching experience to become a teacher. This revolution has changed paradigm of medical education where current teachers are performing different than the way they have been taught. This change has placed a huge gap over medical universities worldwide to propose, implement and revise the development programs for faculty and curricular reforms as to perform the various roles of healthcare educators effectively as teacher, leader, administrator and researcher. ${ }^{3}$

Faculty development programs (FDP) is also known as in house/in service training of faculties. ${ }^{4}$ It is evident from literature that this capacity building steps empowered faculty members to transform them as a change agent as a role of teacher, leader, administrator and researcher. The study conducted in South Africa highlighted the significant features of faculty development programs in medical education such

Kiran Fatima Bana
Senior Lecturer, Department of Health Professional Education
(Dental Section), Bahria University Medical and Dental
College, Karachi
Talea Hoor,
Professor, Department of Pharmacology
Bahria University Medical and Dental College, Karachi
Kulsoom Fatima Rizvi
Vice Principal (Dental Section), Professor, Department of
Community Dentistry
Bahria University Medical and Dental College, Karachi
Received: 09-03-2021
Accepted: 23-03-2021

as collaborative knowledge sharing and support across faculty development program. ${ }^{5}$

Faculty development program scaffolds activities which provide comfort and assistance to the multiple roles of healthcare by enhancing the knowledge, attitude and skills as an individual and by enlarge accelerates the organizational growth. ${ }^{6}$ Faculty development programs can strengthen and elevate the levels of basic competencies in five domains such as teaching, mentoring, curriculum, assessment and organizational leadership. ${ }^{7}$ The implementation of the faculty development program results in sense of inspiration, energy, creativity and support to bring change in faculty perspective and feel them viable during increased workload in complex organizational environment. ${ }^{8}$ Therefore; faculty development program has vital role in academic decision making to sustain the academic process.

Capacity building indicators has a significant impact on the sustainability of any faculty development program as to engage individuals in a collective education development process. Capacity development indicators can provide the future directions for any organizational change to ensure patient safety and targets quality improvements. ${ }^{1}$

There are five themes identified for capacity building indicators in context of courses of basic teaching skills such as innovations in teaching and learning, communication skills development for collaborating at different levels, educational leadership and management development and scholarship development to sustain the faculty development programs. It is evident from the study of Matsika et al in 2019 at Zimbabewe focusing on the role of faculty development programs on medical education and reported that faculty development programs can enhance their confidence to become best teachers, clinicians and researcher. Enhanced attentiveness in research and teaching, interpersonal skills are improved and directed towards new career pathways. ${ }^{9}$ In 2020; Steinert $\mathrm{Y}^{4}$ highlighted in medical teacher that faculty development programs should target all faculty member with diversified roles as educator, teacher, scholar, administrator and leader to enhance the academic performance as a whole.

A part from the five themes identified as a capacity building indicators for faculty development courses of basic teaching skills; peer coaching is extensively used in medical education at clinical setting. ${ }^{10,11}$ It fosters collaborative learning and 
enhance inter professional learning in practice setting. Individual learning goals' identification, observation, timely feedback, support and analysis are the key elements of peer coaching. This facilitates career development, mutual trust and socialization of faculty members by learner centered approach and strengthening the mentor relationship.

Workplace learning is known as pedagogy at workplace. Faculty development can be carried out in ever changing and complex environment such as practice setting, communities and in teaching hospital. Faculty development is often conducted as short courses and workshops which are limited to respond in changing healthcare need at workplace. Hence; there is dire need to strengthen transfer of training. Workplace pedagogy includes guidance at distal or proximal, environmental affordance, feedback and role modeling. Workplace learning can be enhanced by facing the workplace challenges and by orientation from workshop to workplace learning and can boost faculty's motivation and participation in everyday life.

Pedagogy at workplace and peer coaching are closely related in community settings. Practice in communities or communities of practice ( $\mathrm{CoP})$ is a social network of individuals persistently work in communities by understanding the values, beliefs, experiences and history of common practice. Faculty development programs can work to develop the communities of practice by clear objectives. The sustainability of $(\mathrm{CoP})$ is depending upon the development of medical educator of same community. Filho et al in $2019^{12}$; highlighted twelve tips of communities of practices such as specific task to unite members, invite members, gather innovative ideas, ensure institutional support to enhance community awareness and implement best practices in communities. Sense of communities can be enforced by using online technologies among faculty members. ${ }^{12}$ This capacity building indicator for faculty development can support and nurture new faculties from the experiences of educators, teachers, researchers, administrators scholars and leaders worked in communities in sustainable programs. All of them work as a unit for academic development of medical education as a discipline. ${ }^{4}$ The success of faculty development in (CoP) is based on common purpose, dialogues, open communication, guidance and institutional support.

It is interestingly observed that most of faculty development programs are revised in curricula according to the need based analysis of the individual. There are academic competencies framework proposed in literature to design and deliver faculty development program based on program outcomes. A professional medical educator in UK (2014) has developed standards such as five domains and core values for medical educators. These core values are educational scholarship, professional integrity, diversity, equality of opportunities, and respect for patient, learners, colleagues and public. These core values are foundations of five domains of educational development in designing, planning, teaching, assessment, feedback of learners, evidence based practice, educational leadership, educational management and educational research. ${ }^{5}$ To design any faculty development program it must be competency based and reflect the professional identity of faculty as to address creativity, commitment, compassion and passion of the faculty.

Enhancing scholarly activities and research promotion is important capacity building indicator for faculty development. The progress in this indictor has been evident from the literature in medical education as reported by Harden et al in 2018. ${ }^{12}$ Unfortunately; this growth is not paralleled in faculty development programs. The reasons for this unparalleled growth may vary during the process of program design, implementation, policy development for certification and availability of scarce resources for research and scholarly activities. The need of progress in research activities is always acute.

In a nut shell; the primary role of faculty development is academic development. It is recommended that the curricula of faculty development should broaden to support professional identities of teachers. This can be carried out by incorporating peer coaching, utilizing approaches of competency based framework, workplace based learning in communities, role of faculty in researches, leadership development, career development and research promotion. Hence; it will help to monitor the developmental change in organization accordingly.

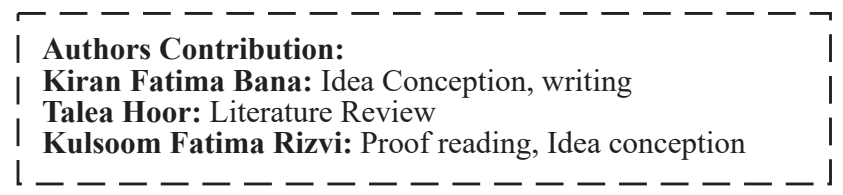

\section{REFERENCES:}

1. Salajegheh M, Gandomkar R, Mirzazadeh A, Sandars J. Identification of capacity development indicators for faculty development programs: A nominal group technique study. BMC Medical Education. 2020; 20:1-8.

2. van Schaik SM, Chang A, Fogh S, Haehn M, Lyndon A, O'Brien B, O'Sullivan P, Ranji S, Rosenbluth G, Sehgal N, Tabas J. Jump-starting faculty development in quality improvement and patient safety education: a team-based approach. Academic Medicine. 2019; 94(11):1728-32.

3. Steinert Y, Mann K, Anderson B, Barnett BM, Centeno A, Naismith L,Prideaux D, Spencer J, Tullo E, Viggiano T, Ward H. A systematic review of faculty development initiatives designed to enhance teaching effectiveness: A 10-year update: BEME Guide No. 40. Med Teacher. 2016; 38(8):769-86.

4. Steinert Y. Faculty development: from rubies to oak. Medical teacher. 2020; 42(4):429-35.

5. Frantz J, Rhoda A, Sandars J, Murdoch-Eaton DB, Marshall M, Burch VC. Understanding faculty development as capacity development: A case study from South Africa. African J Health Professions Educ. 2019;11(2):53-6. 
6. Lee SS, Dong C, Yeo SP, Gwee MC, Samarasekera DD. Impact of faculty development programs for positive behavioural changes among teachers: a case study. Korean J Med Educ. 2018;30(1):11.

7. Guraya, S.Y., Guraya, S.S., Mahabbat, N.A., Fallatah, K.Y., Al-Ahmadi, B.A., ALalawi, H. H. The Desired concept maps and goal setting for assessing professionalism in medicine. J. Clin. Diagn. Res.2016b. 10, JE01-JE05.

8. Abu-Rish Blakeney E, Pfeifle A, Jones M, Hall LW, K. Zierler B. Findings from a mixed-methods study of an interprofessional faculty development program. J Interprofessional Care. 2016;30(1):83-9.
9. Matsika A, Nathoo K, Borok M, Mashaah T, Madya F, Connors S, Campbell T, Hakim JG. Role of faculty development programs in medical education at the University of Zimbabwe College of Health Sciences, Zimbabwe. Annals of global health. 2018;84(1):183-189

10. Hagen MS, Bialek TK, Peterson SL. 2017. The nature of peer coaching: definitions, goals, processes and outcomes. Euro $\mathrm{J}$ of Training and Dev. 41(6):540-558.

11. de Carvalho-Filho MA, Tio RA, Steinert Y. Twelve tips for implementing a community of practice for faculty development. Med Teach. 2019; 1:1-7.

12. Harden RM, Lilley P, McLaughlin J. 2018. Forty years of medical education through the eyes of Medical Teacher: from chrysalis to butterfly. Med Teach. 2018; 40(4):328-330.

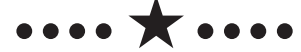

